\title{
RESEARCH
}

Open Access

\section{Association of lysophosphatidic acids with cerebrospinal fluid biomarkers and progression to Alzheimer's disease}

Shahzad Ahmad ${ }^{1 *}$ (D) Adelina Orellana ${ }^{2,3}$, Isabelle Kohler ${ }^{4}$, Lutz Frölich ${ }^{5}$, Itziar de Rojas ${ }^{2,3}$, Silvia Gil ${ }^{2,3}$, Mercè Boada ${ }^{2,3}$, Isabel Hernández ${ }^{2,3}$, Lucrezia Hausner ${ }^{5,6}$, Margot H. M. Bakker ${ }^{7}$, Alfredo Cabrera-Socorro ${ }^{8}$, Najaf Amin ${ }^{1}$, Alfredo Ramírez ${ }^{9,10}$, Agustín Ruiz ${ }^{2,3}$, Thomas Hankemeier ${ }^{1,4^{*}}$ and Cornelia M. Van Duijn $n^{1,11^{*+}}$

\begin{abstract}
Background: Lysophosphatidic acids (LPAs) are bioactive signaling phospholipids that have been implicated in Alzheimer's disease (AD). It is largely unknown whether LPAs are associated with AD pathology and progression from mild cognitive impairment $(\mathrm{MCl})$ to $A D$.

Methods: The current study was performed on cerebrospinal fluid (CSF) and plasma samples of $182 \mathrm{MCl}$ patients from two independent cohorts. We profiled LPA-derived metabolites using liquid chromatography-mass spectrometry. We evaluated the association of LPAs with CSF biomarkers of $A D, A \beta-42$, p-tau, and total tau levels overall and stratified by $A P O E$ genotype and with $M C I$ to $A D$ progression.

Results: Five LPAs (C16:0, C16:1, C22:4, C22:6, and isomer-LPA C22:5) showed significant positive association with CSF biomarkers of AD, A $3-42$, p-tau, and total tau, while LPA C14:0 and C20:1 associated only with A -42 and alkylLPA C18:1, and LPA C20:1 associated with tau pathology biomarkers. Association of cyclic-LPA C16:0 and two LPAs (C20:4, C22:4) with A $3-42$ levels was found only in APOE \&4 carriers. Furthermore, LPA C16:0 and C16:1 also showed association with $\mathrm{MCl}$ to $\mathrm{AD}$ dementia progression, but results did not replicate in an independent cohort.
\end{abstract}

Conclusions: Our findings provide evidence that LPAs may contribute to early AD pathogenesis. Future studies are needed to determine whether LPAs play a role in upstream of AD pathology or are downstream markers of neurodegeneration.

Keywords: Lysophosphatidic acids, Pro-inflammatory phospholipids, Signaling lipids, CSF biomarkers, Alzheimer's disease, $\mathrm{MCl}$

\footnotetext{
*Correspondence: s.ahmad@erasmusmc.nl; hankemeier@lacdr.leidenuniv.nl;

Cornelia.vanDuijn@ndph.ox.ac.uk

${ }^{\dagger}$ Thomas Hankemeier and Cornelia M. Van Duijn contributed equally to this work.

'Department of Epidemiology, Erasmus Medical Centre, Rotterdam, The Netherlands

Full list of author information is available at the end of the article
}

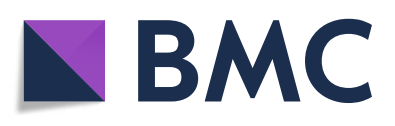

(c) The Author(s). 2020 Open Access This article is licensed under a Creative Commons Attribution 4.0 International License, which permits use, sharing, adaptation, distribution and reproduction in any medium or format, as long as you give appropriate credit to the original author(s) and the source, provide a link to the Creative Commons licence, and indicate if changes were made. The images or other third party material in this article are included in the article's Creative Commons licence, unless indicated otherwise in a credit line to the material. If material is not included in the article's Creative Commons licence and your intended use is not permitted by statutory regulation or exceeds the permitted use, you will need to obtain permission directly from the copyright holder. To view a copy of this licence, visit http://creativecommons.org/licenses/by/4.0/. The Creative Commons Public Domain Dedication waiver (http://creativecommons.org/publicdomain/zero/1.0/) applies to the data made available in this article, unless otherwise stated in a credit line to the data. 


\section{Background}

Lipids play a key role in Alzheimer's disease (AD) [1-3]. Lysophosphatidic acids (LPAs) are bioactive phospholipids representing a significant class of signaling molecules [4]. LPAs regulate a plethora of downstream processes including brain immune response [5], myelination [6], synaptic transmission [7, 8], and synaptic plasticity [9], as well as in endothelial cells and neurovascular function [10]. A recent study has reported altered levels of LPA C18:2 in AD patients compared to controls in plasma [11] and LPAs have been implicated in amyloid-beta $(\mathrm{A} \beta)$ formation [12] and phosphorylation of tau [13] as well, the neuropathological hallmarks of AD. The LPAs may contribute to amyloid pathology, which is supported by their role in enhancing $A \beta$ production through upregulation $\beta$-secretase expression [12]. Moreover, as a bioactive component of oxidized LDL (OxLDL), LPAs affect the integrity of the bloodbrain barrier [14] and are also involved in neuronal cell death $[15,16]$. The mounting evidence for the role of LPA metabolites as a mediator in AD-related molecular process underline their importance in $\mathrm{AD}$ pathophysiology. Nevertheless, studies are lacking investigating the relationship between LPA metabolites with AD biomarkers of pathophysiology.

Encompassing a large group of related metabolites, LPA (1 or 2-acyl-sn-glycero-3-phosphate) metabolites comprises of an sn-glycerol-3 phosphate connected to a fatty acid [17-19]. Molecular species of LPAs differ based on their acyl chain length (C14 to $\mathrm{C} 22)$ and degrees of saturation (C16:1, C18:1, C18:2, C20:3, C20:5, C20:4, C22:4, C22:6) [20]. For example, C18:1 denoting an acyl chain of 18 carbons with a double bond, while C18:2 denotes an acyl chain of 18 carbons with two double bonds [21, 22]. This structural diversity of LPAs also imparts them with differential biological activity [23-25]. Differential biological activity of LPAs can also be attributed to their G-coupled-protein-receptors (GCPR) ranging from $\mathrm{LPA}_{1-5}$, which differ in their affinity and response to diverse LPA species [20, 25]. This structure-activity relationship of LPAs may be relevant to their role in $\mathrm{AD}$ pathophysiology [26]. A comprehensive study of LPA metabolites in AD-related pathology is lacking [14], and the interaction of apolipoprotein $\mathrm{E}$ $(A P O E)$ has not been studied. It is also not known whether LPAs play a role in the progression from mild cognitive impairment (MCI) to AD dementia.

Our study aims to delineate the role of various LPA species in $\mathrm{AD}$ during the prodromal phase of $\mathrm{AD}$, i.e., MCI. We hypothesize that cerebrospinal fluid (CSF) and plasma levels of LPAs may be associated to markers of $\mathrm{AD}$ pathology, including to $\mathrm{A} \beta-42$, phosphorylated tau ( $\mathrm{p}$-tau), and total tau (t-tau) in MCI patients, and this association may be modified by APOE gene. We further hypothesized that LPAs might contribute to $\mathrm{MCI}$ to $\mathrm{AD}$ dementia progression. As prior information on which LPA species may be relevant for the hypothesis, we assessed a series of structurally different LPA metabolites in CSF and plasma.

\section{Methods \\ Study populations}

The current study was performed in cohorts participating in the Alzheimer's Disease Apolipoprotein Pathology for Treatment Elucidation and Development (ADAP TED) consortium including the Barcelona-based memory clinic Fundació ACE (142 CSF-plasma paired samples) and the Department of Geriatric Psychiatry at the Medical Faculty Mannheim, University of Heidelberg (40 CSF samples). Both participating studies are approved by the medical ethical committee of their respective institutes and informed consents were collected from all participants, which allow the use of phenotype and biomarker information for research purpose. From both participating cohorts, we selected MCI patients for which complete information was available on age at blood collection, sex, body mass index (BMI), and lipidlowering medication use, as well as AD biomarkers in CSF (i.e., $A \beta-42$, p-tau, and total tau).

\section{Fundació ACE cohort}

All the MCI patients from the Fundació ACE (ACE) cohort were recruited and assessed between 2016 to 2017 at the Memory Disorders Unit from Fundació ACE, Institut Català de Neurociènces Aplicades, Barcelona, Spain [27]. Each patient was assigned a diagnosis after consensus at a case conference attended by neurologists, neuropsychologists, and social workers. MCI patients fulfilled MCI Petersen's diagnostic criteria $[28,29]$ including subjective memory complaints, decline from normal general cognition, preserved performance in activities of daily living, absence of dementia, and a measurable impairment in one or more cognitive functions, with or without deficit in other cognitive domains (amnestic MCI: single domain or amnestic MCI: multiple domain). At follow-up, dementia was defined according to the DSM-V criteria [30]. The underlying etiologies of the cognitive deficits within the dementia group were classified according to the following criteria: the 2011 National Institute of Aging-Alzheimer's Association (NIA-AA) [31] for Alzheimer's disease and the National Institute of Neurological Disorder and Stroke and Association Internationale pour la Recherche et l'Enseignement in Neurosciences criteria(NINDS-AIREN) [32] for vascular dementia, frontotemporal dementia [33], and Lewy body dementia [34].

Paired samples of CSF and plasma were collected from patients under fasted conditions. CSF was obtained by 
lumbar puncture following the established consensus recommendations [35]. Briefly, the lumbar puncture (LP) was performed by an experienced neurologist with the patients in a sitting position. After local anesthesia (1\% mepivacaine) was injected subcutaneously, CSF was obtained by LP in the intervertebral space of L3-L4. The fluid was collected passively in two 10-ml polypropylene tubes (Sarstedt ref. 62610018). The first tube of CSF was analyzed for basic biochemistry (glucose, total proteins, proteinogram, and cell type and cell number). The second tube was centrifuged $\left(2000 \times g 10 \mathrm{~min}\right.$ at $\left.4{ }^{\circ} \mathrm{C}\right)$, and the fluid was aliquoted into polypropylene tubes (Sarstedt ref. 72694007) and stored at $-80^{\circ} \mathrm{C}$ until analysis. The time delay between CSF collection and storage was less than $2 \mathrm{~h}$. On the same day as the $\mathrm{AD}$ biomarker analysis (A $\beta-42$, $\mathrm{p}$-tau, and total tau), an aliquot was thawed at room temperature and vortexed for 5-10 s. CSF $A \beta 1-42$, total tau, and p-tau levels were measured using commercially available enzyme-linked immunosorbent assays, namely Innotest A $\beta 1-42$, Innotest hTAU $\mathrm{Ag}$, and Innotest PHOSPHO-TAU (181P) (Innotest, Fujirebio Europe) [35, 36].

For $A P O E$ genotyping in the $\mathrm{ACE}$ cohort, genomic DNA was obtained from whole blood collected in BD Vacutainer tubes (K2-EDTA). DNA extraction was performed using DNA Chemagen technology (Perkin Elmer). Afterward, the $A P O E$ genotype was determined by TaqMan probes analysis in a system of Real-Time PCR QuantStudio3 (Thermofisher).

\section{Heidelberg/Mannheim memory clinic sample}

Forty MCI patients were recruited and assessed between 2012 to 2016 at the Memory Clinic of the Central Institute of Mental Health (Mannheim, Germany). Neuropsychiatric or general medical causes of impaired cognition were excluded by detailed medical history, physical and neuropsychiatric examination, and standard serum laboratory assessment. Thus, all MCI patients met the MCI Petersen's diagnostic criteria [28, 29] including subjective memory complaints, normal general cognition, only minimally impaired performance in instrumental activities of daily living, absence of dementia, and a measurable impairment in one or more cognitive domains. Cognitive impairment was defined as performance below 1.2 standard deviation in one or more cognitive domains in standard neuropsychological test battery [37] (test battery of the Consortium to Establish a Registry for Alzheimer Disease (CERAD) [38] plus the Wechsler memory scale - logical memory (WMS) immediate and delayed recall [39] and the trail making test A (TMT-A) and B (TMT-B) [40]. For biomarker assessments, lumbar puncture was performed to determine amyloid pathology in CSF following the NIA/AA criteria for the diagnosis of MCI due to AD [41]. The results of the clinical assessment for each patient were discussed at a case conference attended by geriatric psychiatrists and neuropsychologists. The diagnosis of MCI due to $\mathrm{AD}$ or prodromal $\mathrm{AD}$ [42] was assigned by consensus using all clinical and biomarker data (CSF A $\beta-42$, t-tau, and p-tau). Paired samples of CSF and plasma were collected from patients according to the established consensus recommendations [35]. Aliquots were stored in polypropylene tubes at $-80^{\circ} \mathrm{C}$. A $\beta 1-42$, p-tau, and t-tau were performed in the Neurochemistry Laboratory at the Department of Neurology, University Medical School, Göttingen, using established protocols. P-tau levels in CSF were quantified with a commercially available ELISA kit [INNOTEST ${ }^{\circ}$ PHOSPHO-TAU(181P), Innogenetics]. A $\beta 1-42$ was detected with a commercially available ELISA kit [INNOTEST ${ }^{\circ} \beta$ - AMYLOID (1-42) Innogenetics] for quantitative analysis.

$A P O E$ genotyping in Heidelberg/Mannheim memory clinic sample was performed on an Illumina GSA1.0 SharedCustom Content bead array according to the manufacturer's instructions. GenomeStudio 2.0 software was used to determine $A P O E$ genotypes and results were exported in PLINK format.

\section{Metabolomics profiling}

All CSF and plasma samples of both cohorts were profiled for the same set of metabolites using a UHPLCMS/MS approach targeting signaling lipid mediators including LPAs, alkyl-lysophosphatidic acid (aLPAs), and cyclic-lysophosphatidic acids (cLPAs) ranging from C14 to C22 acyl chain length [43].

Samples were stored at $-80^{\circ} \mathrm{C}$, thawed at room temperature, and randomized prior to analysis. Quality control (QC) samples, consisting of a pool of all samples, and blanks were also analyzed to ensure the quality of the obtained data. For CSF samples, $350 \mu \mathrm{L}$ of samples were evaporated to dryness, spiked with isotopically labeled internal standards and antioxidant (BHT:EDTA 1: $1,0.2 \mathrm{mg} / \mathrm{mL}$ ), and reconstituted in two aliquots using a mixture of methanol to water (70:30, v/v). Plasma samples were first acidified through the addition of $0.2 \mathrm{M}$ citric acid and $0.1 \mathrm{M}$ disodium hydrogen phosphate buffer at $\mathrm{pH}$ 4.5. Metabolites were extracted using liquidliquid extraction with a mixture of 1-butanol:ethyl acetate $(1: 1, \mathrm{v} / \mathrm{v})$ prior to mixing, centrifugation, collection of the supernatant, evaporation, and reconstitution into two aliquots with a mixture of ice-cold methanol to water $(70: 30, \mathrm{v} / \mathrm{v})$.

Samples were measured using a Shimadzu LC-30 AD system coupled to a LCMS-8050 Triple Quadrupole system (Shimadzu, Japan).

For both plasma and CSF samples, the first aliquot (high $\mathrm{pH}$ injection) was analyzed using a Kromasil EternityXT-1.8 C18 column, $2.1 \times 50$ mm, $1.8 \mu \mathrm{m}$ (Akzo 
Nobel, Netherlands) with a mobile phase composed of (A) water with $5 \mathrm{mM}$ ammonium acetate and $0.0625 \%$ ammonium hydroxide and (B) $80 \%$ acetonitrile with $20 \%$ isopropanol and $0.1 \%$ ammonium hydroxide. For both matrices, the second aliquot (low $\mathrm{pH}$ injection) was analyzed using an Acquity BEH C18 column, $2.1 \times 50 \mathrm{~mm}, 1.7 \mu \mathrm{m}$ (Waters) with a mobile phase composed of (A) water with $0.1 \%$ acetic acid, (B) $75 \%$ acetonitrile with $25 \%$ methanol and $0.1 \%$ acetic acid, and (C) 100\% isopropanol. For both $\mathrm{pH}$ injections, polarity switching and dynamic multiple reaction monitoring (dMRM) mode were used for MS acquisition.

To perform the QC, metabolites showing a relative standard deviation (RSD) higher than $30 \%$ on corrected peak areas in QC samples were excluded. After QC correction, 19 and 17 LPAs in CSF and plasma, respectively, were used for further data analysis (Supplementary Table 1). Common metabolites detected in both CSF and plasma included LPAs (C14:0, C14:1, C14:2, C16:0, C18:0, C18:1, C18:2, C20:1, C20:3, C20:5, C22:4, C22:5) and three cyclic-LPAs (C16:0, C18:0, C18:1). Metabolites only detected in CSF samples included some LPAs (C20: 4, C22:6, C22:5) and an alkyl-LPA C16:1. LPA C18:3 and two cyclic-LPAs (C18:2, C20:4) were detected only in plasma samples. The inverse rank transformation was used to normalize the distribution of metabolites in both cohorts.

\section{Statistical analysis}

Association of LPAs with A $\beta$-42, p-tau, and t-tau We performed linear regression analysis to test the association of $A \beta-42$, $p$-tau, and $t$-tau with the profiled metabolites in paired CSF and plasma samples from the ACE cohort and CSF samples from Heidelberg-Manheim memory clinic. Levels of $A \beta-42$, p-tau, and $t$-tau in CSF were used as the outcome variable in the regression model. Analyses were adjusted for age, sex, body mass index (BMI), and lipid-lowering medications. The inverse rank transformation was applied to normalize the distribution of both CSF AD biomarkers (A $\beta-42$, p-tau, and $\mathrm{t}$-tau) and LPA metabolite levels in CSF and plasma. A meta-analysis of the regression analysis results of the two cohorts was performed using METAL software [44] using the inverse-variance fixed-effect model. Metaanalysis results of associations were also corrected for multiple testing separately for each $\mathrm{AD}$ biomarker using false discovery rate $(F D R)$ by the Benjamini and Hochberg method [45] and findings with $F D R<0.05$ were considered significant in the overall analysis. All analyses were performed in $\mathrm{R}$ (https://www.r-project.org/). To test whether conversion from LPA to another was relevant, we have tested all ratios between LPAs.

APOE-stratified regression analysis To identify $A P O E$-specific associations of metabolites with $\mathrm{AD}$ biomarkers, $A P O E$-stratified analyses were performed in both participating cohorts based on three $A P O E$ strata including $A P O E$ 44/34/24, APOE 33, and APOE 22/23. In the stratified analyses, subjects with $A P O E 24$ genotype were pooled with patients having $A P O E$ 44/34 genotypes based on their similar risk profiles, as reported in an earlier study [46]. APOE-stratified analyses results were reported as a combined meta-analysis of both datasets included in the current study (ACE cohort and Heidelberg/Manheim cohort). Due to the smaller number of APOE 22/23 carriers in the two datasets, a combined regression analysis was performed, aggregating all $A P O E$ $22 / 23$ carriers from two cohorts while adjusting for cohort effects. Multiple testing correction was performed using the false-discovery rate $(F D R<0.05)$ based on Benjamin and Hochberg [45].

To assess the association of the $A P O E$ genotype with LPAs, we compared levels of LPAs in CSF of APOE $\varepsilon 4$ ( $A P O E$ 44/34/24) and $A P O E$ \&2 (22/23) carriers versus $A P O E$ \&33 carriers using regression analysis adjusting for the age, sex, BMI, and lipid-lowering medications. This regression analysis was conducted for each cohort and their combined meta-analysis.

MCI to AD dementia progression analysis In the ACE cohort, follow-up information was available for 138 out of $142 \mathrm{MCI}$ patients including 17 non-amnestic and 121 amnestic MCIs. A total of $43 \mathrm{MCI}$ patients progressed into $\mathrm{AD}$ dementia (31\%) during follow-up, while $95 \mathrm{MCI}$ patients did not convert to $\mathrm{AD}$ dementia. The mean follow-up time in converters was 1.42 years $(\mathrm{SD}=0.53)$ and 1.44 years $(\mathrm{SD}=0.70)$ in non-converters. The rate of $\mathrm{MCI}$ to $\mathrm{AD}$ dementia progression in our sample is similar to other clinic-based studies [47]. We analyzed the association of LPAs with MCI to AD dementia progression using the cox proportional hazard model adjusting for age at blood collection, sex, BMI, and lipid-lowering medication use. In the ACE cohort, $11 \mathrm{MCI}$ patients also progressed to other types of dementia including vascular dementia $(n=6)$, semantic dementia $(n=1)$, Parkinson dementia $(n=1)$, Lewy Body dementia $(n=2)$, and frontal temporal dementia $(n=1)$. We repeated the conversion analysis in the Heidelberg/Mannheim cohort. Among the $40 \mathrm{MCIs}, 23$ converted to AD dementia. The mean follow-up time in the Heidelberg/Mannheim cohort was 1.80 years $(\mathrm{SD}=1.06)$. Three $\mathrm{MCI}$ patients also progressed to frontal temporal dementia in this sample.

Association of cognitive measures with LPA levels We also assessed the association of cognitive measures, MMSE, and CDR with LPAs levels in CSF of both ACE and Heidelberg/Mannheim cohort. We used linear regression analysis adjusted for age, sex, BMI, and lipidlowering medication. Results were meta-analyzed using 
Table 1 Population descriptive

\begin{tabular}{|c|c|c|c|}
\hline & ACE cohort & Heidelberg/Mannheim cohort & $P$ value of difference \\
\hline MCl patients $(N)$ & 142 & 40 & \\
\hline Metabolomics profiling tissue & CSF and plasma & CSF & \\
\hline Age (SD) blood collection, years & $71.94(7.74)$ & $68.85(8.50)$ & 0.042 \\
\hline Female (\%) & $74(52 \%)$ & $22(55 \%)$ & 0.747 \\
\hline Body mass index (SD) & $26.46(3.74)$ & $25.85(3.61)$ & 0.353 \\
\hline Lipid-lowering medication user (\%) & $63(44 \%)$ & $11(27 \%)$ & 0.055 \\
\hline Amyloid-beta 42 in pg/mL (SD) & 791.59 (337.36) & $690.84(397.13)$ & 0.151 \\
\hline P-Tau in pg/mL (SD) & $71.37(37.30)$ & $63.17(29.96)$ & 0.153 \\
\hline Total tau in pg/mL (SD) & $478.82(253.45)$ & 380.95 (326.97) & 0.124 \\
\hline MMSE & $24.93(4.07)$ & $26.55(2.51)$ & $2.67 \times 10^{-3}$ \\
\hline CDR & $0.50(0.06)$ & $0.55(0.15)$ & 0.047 \\
\hline \multicolumn{4}{|l|}{ APOE genotype $\mathrm{N}(\%)$} \\
\hline APOE 44/34/24 & $50(35 \%)$ & $18(45 \%)$ & \\
\hline APOE 33 & $81(57 \%)$ & $18(45 \%)$ & \\
\hline APOE 22/23 & $11(8 \%)$ & $4(10 \%)$ & \\
\hline
\end{tabular}

Abbreviations: $M C l$ mild cognitive impairment, $S D$ standard deviation, CSF cerebrospinal fluid, MMSE the Mini-Mental State Examination, CDR clinical dementia rating, $A P O E$ apolipoprotein E gene

Table 2 Association of cerebrospinal fluid (CSF) level of metabolites with Aß-42 levels in CSF

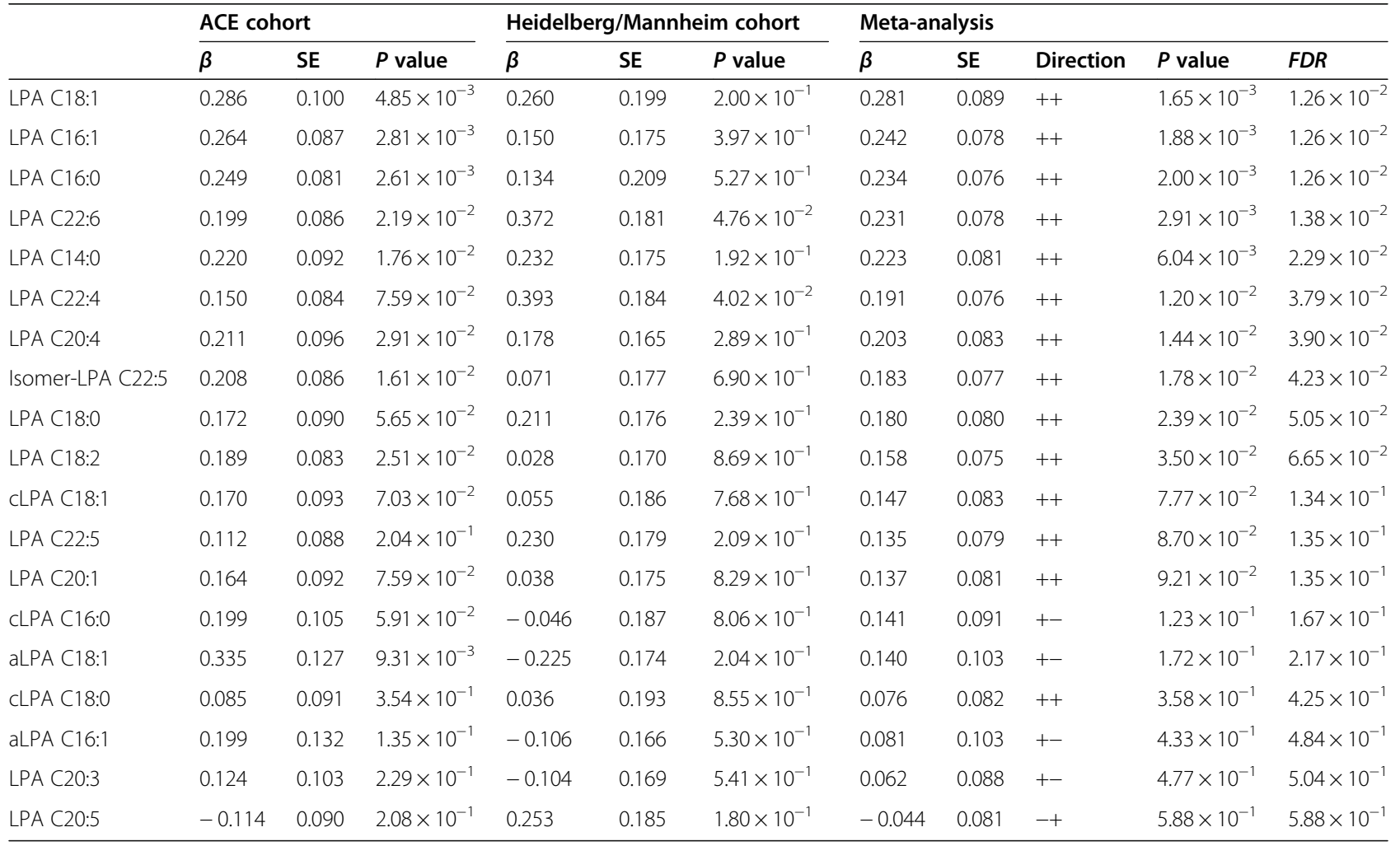


METAL software [44] using the inverse-variance fixedeffect model and multiple testing was performed using false discovery rate $(F D R)$ by the Benjamini and Hochberg method [45].

\section{Results}

\section{General characteristics}

The general characteristic of the ACE and Heidelberg/ Mannheim cohorts are provided in Table 1. The patients of the ACE cohort of Barcelona are on average 3 years older $(P=0.042)$ than the Heidelberg/Mannheim cohort. The proportion of women is similar between the two cohorts $(P=0.747)$. The proportion of patients treated with lipid-lowering medication in the ACE cohort (44\%) is 1.6 times $(P=0.055)$ higher compared to that in the Heidelberg/Mannheim series of patients. The levels of $A \beta-42$, ptau, and t-tau in CSF between the two cohorts were not significantly different. In terms of basic cognitive measures, the Mini-Mental State Examination (MMSE) score $\left(P=2.67 \times 10^{-3}\right)$ and clinical dementia rating $(\mathrm{CDR})$ score $(P=0.047)$ was significantly higher in Heidelberg/Mannheim cohort compared to ACE cohort.

\section{Association of LPAs with CSF A $\beta-42$, p-tau, and total tau}

Findings of the association of the metabolites with $A \beta$ 42 levels in CSF are provided in Table 2. In a meta- analysis, eight LPAs including C18:1 $(\beta=0.281, P=$ $\left.1.65 \times 10^{-3}\right), \quad$ C16:1 $\quad\left(\beta=0.242, \quad P=1.88 \times 10^{-3}\right), \quad C 16: 0$ $\left(\beta=0.234, \quad P=2 \times 10^{-3}\right), \quad \mathrm{C} 22: 6 \quad(\beta=0.231, \quad P=2.91 \times$ $\left.10^{-3}\right), \mathrm{C} 14: 0\left(\beta=0.223, P=6.04 \times 10^{-3}\right), \mathrm{C} 22: 4(\beta=0.191$, $\left.P=1.20 \times 10^{-2}\right), C 20: 4 \quad\left(\beta=0.203, P=1.44 \times 10^{-2}\right)$, and isomer-LPA C22:5 $\left(\beta=0.183, P=1.78 \times 10^{-2}\right)$ showed positive association with $A \beta-42$ levels in CSF. The effect estimates $(\beta)$ of all associated LPAs were in the same direction in both cohorts.

Six LPAs, C20:1 $\left(\beta=0.347, P=7.11 \times 10^{-6}\right)$, isomerLPA C22:5 $\left(\beta=0.328, P=8.68 \times 10^{-6}\right)$, C22:6 $(\beta=0.270$, $\left.P=4.03 \times 10^{-4}\right), \mathrm{C} 16: 0\left(\beta=0.230, P=2.26 \times 10^{-3}\right), \mathrm{C} 16: 1$ $\left(\beta=0.206, P=8.23 \times 10^{-3}\right)$, and $C 22: 4 \quad(\beta=0.186, P=$ $\left.1.39 \times 10^{-2}\right)$ showed significant association $(F D R<0.05)$ with p-tau levels in CSF. In terms of the direction of effects, the regression coefficients $(\beta)$ were very similar across two cohorts (Table 3).

Findings for $\mathrm{t}$-tau levels in CSF were very similar as those for p-tau levels (Table 4), with five LPAs including C20:1, isomer-LPA C22:5, C22:6, C16:0, C16:1, C22:4, C18:1, and alkyl-LPA C18:1 showing significant positive association $(F D R<0.05)$ with total tau levels in CSF. Among the identified metabolites, LPA C18:1 and alkylLPA C18:1 showed association with only total tau but not with p-tau levels.

Table 3 Association of cerebrospinal fluid (CSF) level of metabolites with p-tau levels in CSF

\begin{tabular}{|c|c|c|c|c|c|c|c|c|c|c|c|}
\hline & \multicolumn{3}{|c|}{ ACE cohort } & \multicolumn{3}{|c|}{ Heidelberg/Mannheim cohort } & \multicolumn{5}{|c|}{ Meta-analysis } \\
\hline & $\beta$ & SE & $P$ value & $\beta$ & SE & $P$ value & $\beta$ & SE & Direction & $P$ value & $F D R$ \\
\hline LPA C20:1 & 0.350 & 0.086 & $8.16 \times 10^{-5}$ & 0.333 & 0.174 & $6.42 \times 10^{-2}$ & 0.347 & 0.077 & ++ & $7.11 \times 10^{-6}$ & $8.25 \times 10^{-5}$ \\
\hline Isomer-LPA C22:5 & 0.302 & 0.082 & $3.15 \times 10^{-4}$ & 0.438 & 0.170 & $1.46 \times 10^{-2}$ & 0.328 & 0.074 & ++ & $8.68 \times 10^{-6}$ & $8.25 \times 10^{-5}$ \\
\hline LPA C22:6 & 0.279 & 0.083 & $9.39 \times 10^{-4}$ & 0.214 & 0.198 & $2.88 \times 10^{-1}$ & 0.270 & 0.076 & ++ & $4.03 \times 10^{-4}$ & $2.55 \times 10^{-3}$ \\
\hline LPA C16:0 & 0.218 & 0.080 & $7.67 \times 10^{-3}$ & 0.316 & 0.214 & $1.48 \times 10^{-1}$ & 0.230 & 0.075 & ++ & $2.26 \times 10^{-3}$ & $1.07 \times 10^{-2}$ \\
\hline LPA C16:1 & 0.226 & 0.086 & $9.49 \times 10^{-3}$ & 0.112 & 0.182 & $5.43 \times 10^{-1}$ & 0.206 & 0.078 & ++ & $8.23 \times 10^{-3}$ & $3.13 \times 10^{-2}$ \\
\hline LPA C22:4 & 0.168 & 0.082 & $4.17 \times 10^{-2}$ & 0.287 & 0.196 & $1.53 \times 10^{-1}$ & 0.186 & 0.076 & ++ & $1.39 \times 10^{-2}$ & $4.40 \times 10^{-2}$ \\
\hline LPA C18:1 & 0.217 & 0.099 & $3.08 \times 10^{-2}$ & 0.171 & 0.212 & $4.25 \times 10^{-1}$ & 0.209 & 0.090 & ++ & $2.04 \times 10^{-2}$ & $5.54 \times 10^{-2}$ \\
\hline aLPA C18:1 & 0.110 & 0.128 & $3.91 \times 10^{-1}$ & 0.425 & 0.169 & $1.69 \times 10^{-2}$ & 0.224 & 0.102 & ++ & $2.79 \times 10^{-2}$ & $6.62 \times 10^{-2}$ \\
\hline CLPA C18:0 & 0.159 & 0.089 & $7.53 \times 10^{-2}$ & 0.243 & 0.197 & $2.26 \times 10^{-1}$ & 0.173 & 0.081 & ++ & $3.23 \times 10^{-2}$ & $6.82 \times 10^{-2}$ \\
\hline LPA C20:3 & 0.072 & 0.101 & $4.79 \times 10^{-1}$ & 0.380 & 0.163 & $2.62 \times 10^{-2}$ & 0.157 & 0.086 & ++ & $6.77 \times 10^{-2}$ & $1.29 \times 10^{-1}$ \\
\hline CLPA C18:1 & 0.115 & 0.092 & $2.14 \times 10^{-1}$ & 0.265 & 0.189 & $1.69 \times 10^{-1}$ & 0.144 & 0.083 & ++ & $8.25 \times 10^{-2}$ & $1.42 \times 10^{-1}$ \\
\hline LPA C14:0 & 0.129 & 0.091 & $1.60 \times 10^{-1}$ & 0.088 & 0.187 & $6.42 \times 10^{-1}$ & 0.121 & 0.082 & ++ & $1.40 \times 10^{1}$ & $2.12 \times 10^{-1}$ \\
\hline LPA C22:5 & 0.065 & 0.087 & $4.56 \times 10^{-1}$ & 0.326 & 0.184 & $8.51 \times 10^{-2}$ & 0.112 & 0.078 & ++ & $1.52 \times 10^{-1}$ & $2.12 \times 10^{-1}$ \\
\hline aLPA C16:1 & 0.061 & 0.131 & $6.42 \times 10^{-1}$ & 0.287 & 0.168 & $9.65 \times 10^{-2}$ & 0.146 & 0.103 & ++ & $1.56 \times 10^{-1}$ & $2.12 \times 10^{-1}$ \\
\hline LPA C18:0 & 0.096 & 0.089 & $2.82 \times 10^{-1}$ & 0.077 & 0.188 & $6.86 \times 10^{-1}$ & 0.092 & 0.080 & ++ & $2.50 \times 10^{-1}$ & $3.16 \times 10^{-1}$ \\
\hline LPA C18:2 & -0.094 & 0.083 & $2.60 \times 10^{-1}$ & -0.024 & 0.175 & $8.90 \times 10^{-1}$ & -0.081 & 0.075 & - & $2.79 \times 10^{-1}$ & $3.30 \times 10^{-1}$ \\
\hline CLPA C16:0 & 0.102 & 0.104 & $3.28 \times 10^{-1}$ & 0.075 & 0.196 & $7.04 \times 10^{-1}$ & 0.096 & 0.092 & ++ & $2.95 \times 10^{-1}$ & $3.30 \times 10^{-1}$ \\
\hline LPA C20:4 & 0.077 & 0.095 & $4.20 \times 10^{-1}$ & 0.081 & 0.176 & $6.49 \times 10^{-1}$ & 0.078 & 0.084 & ++ & $3.53 \times 10^{-1}$ & $3.72 \times 10^{-1}$ \\
\hline LPA C20:5 & -0.028 & 0.088 & $7.54 \times 10^{-1}$ & 0.114 & 0.193 & $5.59 \times 10^{-1}$ & -0.003 & 0.081 & -+ & $9.68 \times 10^{-1}$ & $9.68 \times 10^{-1}$ \\
\hline
\end{tabular}

Direction column indicates the direction of regression coefficient of association in the ACE and Heidelberg/Mannheim cohort respectively 
Table 4 Association of cerebrospinal fluid (CSF) level of metabolites with t-tau levels in CSF

\begin{tabular}{|c|c|c|c|c|c|c|c|c|c|c|c|}
\hline & \multicolumn{3}{|c|}{ ACE cohort } & \multicolumn{3}{|c|}{ Heidelberg/Mannheim cohort } & \multicolumn{5}{|c|}{ Meta-analysis } \\
\hline & $\bar{\beta}$ & SE & $P$ value & $\bar{\beta}$ & SE & $P$ value & $\bar{\beta}$ & SE & Direction & $P$ value & $F D R$ \\
\hline LPA C20:1 & 0.318 & 0.085 & $2.89 \times 10^{-4}$ & 0.391 & 0.181 & $3.76 \times 10^{-2}$ & 0.331 & 0.077 & ++ & $1.79 \times 10^{-5}$ & $3.40 \times 10^{-4}$ \\
\hline Isomer-LPA C22:5 & 0.271 & 0.081 & $1.05 \times 10^{-3}$ & 0.390 & 0.184 & $4.14 \times 10^{-2}$ & 0.290 & 0.074 & ++ & $8.88 \times 10^{-5}$ & $8.07 \times 10^{-4}$ \\
\hline LPA C22:6 & 0.268 & 0.081 & $1.22 \times 10^{-3}$ & 0.409 & 0.200 & $4.84 \times 10^{-2}$ & 0.288 & 0.075 & ++ & $1.27 \times 10^{-4}$ & $8.07 \times 10^{-4}$ \\
\hline LPA C16:0 & 0.227 & 0.079 & $4.42 \times 10^{-3}$ & 0.461 & 0.218 & $4.18 \times 10^{-2}$ & 0.254 & 0.074 & ++ & $5.80 \times 10^{-4}$ & $2.75 \times 10^{-3}$ \\
\hline LPA C16:1 & 0.236 & 0.084 & $5.67 \times 10^{-3}$ & 0.280 & 0.187 & $1.44 \times 10^{-1}$ & 0.244 & 0.077 & ++ & $1.48 \times 10^{-3}$ & $5.63 \times 10^{-3}$ \\
\hline LPA C22:4 & 0.185 & 0.080 & $2.21 \times 10^{-2}$ & 0.361 & 0.203 & $8.51 \times 10^{-2}$ & 0.209 & 0.074 & ++ & $5.05 \times 10^{-3}$ & $1.60 \times 10^{-2}$ \\
\hline LPA C18:1 & 0.230 & 0.097 & $1.93 \times 10^{-2}$ & 0.190 & 0.223 & $3.99 \times 10^{-1}$ & 0.224 & 0.089 & ++ & $1.20 \times 10^{-2}$ & $3.26 \times 10^{-2}$ \\
\hline aLPA C18:1 & 0.125 & 0.125 & $3.18 \times 10^{-1}$ & 0.488 & 0.175 & $8.52 \times 10^{-3}$ & 0.248 & 0.102 & ++ & $1.46 \times 10^{-2}$ & $3.48 \times 10^{-2}$ \\
\hline LPA C20:3 & 0.070 & 0.099 & $4.83 \times 10^{-1}$ & 0.504 & 0.163 & $4.06 \times 10^{-3}$ & 0.187 & 0.085 & ++ & $2.78 \times 10^{-2}$ & $5.86 \times 10^{-2}$ \\
\hline LPA C14:0 & 0.156 & 0.089 & $8.13 \times 10^{-2}$ & 0.196 & 0.194 & $3.19 \times 10^{-1}$ & 0.163 & 0.081 & ++ & $4.36 \times 10^{-2}$ & $7.58 \times 10^{-2}$ \\
\hline CLPA C18:0 & 0.166 & 0.087 & $5.88 \times 10^{-2}$ & 0.140 & 0.210 & $5.11 \times 10^{-1}$ & 0.162 & 0.080 & ++ & $4.39 \times 10^{-2}$ & $7.58 \times 10^{-2}$ \\
\hline aLPA C16:1 & 0.093 & 0.128 & $4.70 \times 10^{-1}$ & 0.377 & 0.172 & $3.54 \times 10^{-2}$ & 0.194 & 0.103 & ++ & $5.89 \times 10^{-2}$ & $9.32 \times 10^{-2}$ \\
\hline CLPA C18:1 & 0.110 & 0.090 & $2.26 \times 10^{-1}$ & 0.202 & 0.201 & $3.21 \times 10^{-1}$ & 0.126 & 0.082 & ++ & $1.28 \times 10^{-1}$ & $1.87 \times 10^{-1}$ \\
\hline LPA C20:4 & 0.084 & 0.094 & $3.68 \times 10^{-1}$ & 0.245 & 0.180 & $1.83 \times 10^{-1}$ & 0.119 & 0.083 & ++ & $1.54 \times 10^{-1}$ & $2.08 \times 10^{-1}$ \\
\hline LPA C18:0 & 0.112 & 0.087 & $2.01 \times 10^{-1}$ & 0.050 & 0.198 & $8.03 \times 10^{-1}$ & 0.102 & 0.080 & ++ & $2.01 \times 10^{-1}$ & $2.55 \times 10^{-1}$ \\
\hline LPA C22:5 & 0.026 & 0.085 & $7.59 \times 10^{-1}$ & 0.407 & 0.189 & $3.88 \times 10^{-2}$ & 0.090 & 0.078 & ++ & $2.46 \times 10^{-1}$ & $2.92 \times 10^{-1}$ \\
\hline CLPA C16:0 & 0.110 & 0.102 & $2.83 \times 10^{-1}$ & 0.021 & 0.207 & $9.18 \times 10^{-1}$ & 0.092 & 0.091 & ++ & $3.11 \times 10^{-1}$ & $3.48 \times 10^{-1}$ \\
\hline LPA C18:2 & -0.041 & 0.082 & $6.19 \times 10^{-1}$ & 0.106 & 0.183 & $5.66 \times 10^{-1}$ & -0.016 & 0.075 & -+ & $8.27 \times 10^{-1}$ & $8.60 \times 10^{-1}$ \\
\hline LPA C20:5 & -0.007 & 0.087 & $9.39 \times 10^{-1}$ & 0.128 & 0.203 & $5.34 \times 10^{-1}$ & 0.014 & 0.080 & -+ & $8.60 \times 10^{-1}$ & $8.60 \times 10^{-1}$ \\
\hline
\end{tabular}

Direction column indicates the direction of regression coefficient of association in the ACE and Heidelberg/Mannheim cohort respectively

Abbreviations: LPA lysophosphatidic acid, CLPA cyclic lysophosphatidic acid, aLPA alkyl-Lysophosphatidic acid, SE standard error, FDR false discovery rate

Figure 1a shows a heatmap comparing $A \beta-42$, $p$-tau, and $t$-tau in CSF. The pattern of association is very similar for amyloid and tau biomarkers except for two LPAs (C14:0, C20:4) showing association to only $A \beta-42$ and an alkyl-LPA C18:1 showing a unique relation to total tau levels in CSF. Correlation plots are provided in Fig. 1 for five LPAs (C16:0. C16:1, C22:4, C22:6, isomer-LPA C22: $5)$, which showed significant association with all three AD biomarkers (A $\beta-42, p$-tau, and $t$-tau). The analysis of the ratios did not yield any significant findings.

In the regression analysis of LPAs in plasma (Supplementary Table 2), no significant association was found with $A \beta-$ 42, p-tau, or with t-tau in ACE cohort. Correlation analysis between CSF and plasma levels of LPAs for which paired samples were available (Supplementary Fig. 1) shows that levels of 8 LPAs were significantly correlated between CSF and plasma: cyclic-LPA C16:0 $\left(R=-0.28, P=9.4 \times 10^{-4}\right)$, cyclic-LPA C18:1 $(R=-0.18, P=0.029)$, LPA C18:1 $(R=$ $\left.0.44, P=4.5 \times 10^{-8}\right)$, LPA C20:1 $\left(R=-0.23, P=6.2 \times 10^{-3}\right)$, and LPA C20:5 $\left(R=0.4, P=1.2 \times 10^{-6}\right)$.

\section{The role of $A P O E$ in the association between LPA levels and CSF AD biomarkers}

The results of meta-analysis of association results of $A P O E$-stratified analyses are provided in Fig. 2. APOEstratified analysis of $A \beta-42$ (Fig. 2a) showed that LPAs species which showed significant association in the overall meta-analysis (C14:0, C16:0, C16:1, C18:1, C20:4, C22:4, C22:6, isomer-LPA C22:5) were restricted to $A P O E$ \&33 (LPA C16:0, C18:0, C22:6, isomer-LPA C22:5) and $A P O E$ \&4 (LPA C20:4, C22:4) carriers while in $A P O E$ $22 / 23$ carriers, the association was not significant and in the opposite direction. Based on statistical significance, we observed a few unique associations in the APOE4 stratum involving a cyclic-LPA C16:0 and in the APOE33 stratum LPAs C18:0, which did not show significant association in overall regression analysis. Although the level of statistical significance differed between $A P O E \& 33$ and $A P O E \& 4$ carriers, the direction of association was always similar.

For p-tau and t-tau levels, significant association was observed with isomer-LPA C22:5 in APOE 33 and APOE $\varepsilon 4$ carriers (Fig. 2b, c). Further significant association was observed between LPA C20:1 and p-tau and three LPAs (C16:0, C16:1, C22:4) and t-tau only in APOE 33 carriers.

As $A P O E$ appeared to modify the association between various metabolites and CSF biomarkers, we tested whether the $A P O E$ genotype is associated with levels of the metabolites associated with biomarkers in the overall and $A P O E$-stratified analyses (see Supplementary Table 3 and 4). We did not observe significant differences 


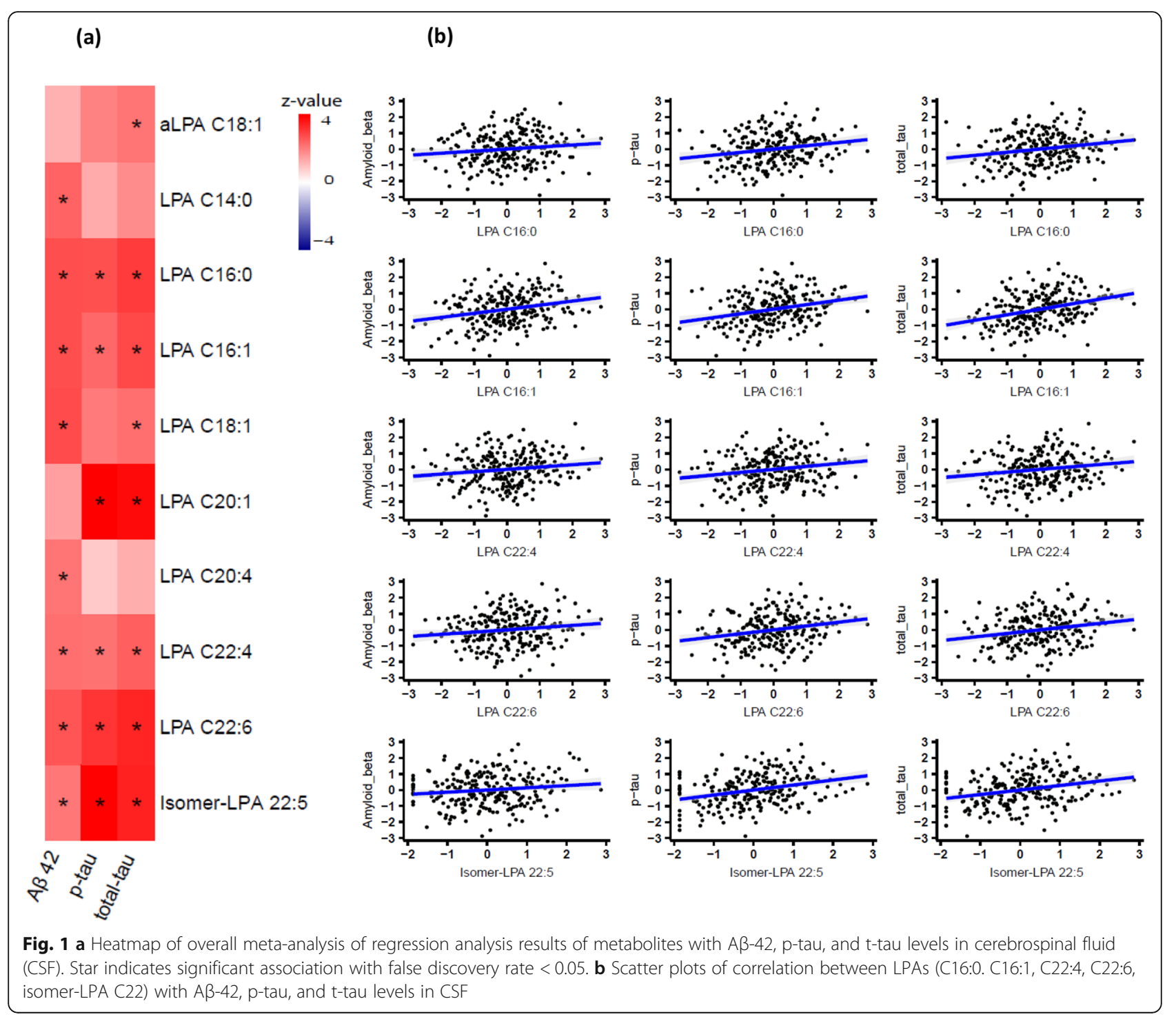

between $A P O E \& 4$ versus $A P O E$ \&33 carriers and $A P O E$ $\varepsilon 2$ versus $A P O E 33$ carriers in the combined metaanalysis of the two datasets. Although cLPA C18:1 showed suggestive association with $A P O E \varepsilon 2$ in the combined meta-analysis $\left(\beta=-0.636, P=4.66 \times 10^{-3}, F D R=\right.$ $8.85 \times 10^{-2}$ ) but did not pass multiple testing.

\section{$\mathrm{MCl}$ to $\mathrm{AD}$ dementia progression}

In the ACE cohort, LPA C16:1 $(\beta=-0.472, P=3.25 \times$ $\left.10^{-3}, F D R=4.41 \times 10^{-2}\right)$ and LPA C16:0 $(\beta=-0.412$, $P=4.64 \times 10^{-3}, \quad F D R=4.41 \times 10^{-2}$ ) were significantly associated with progression from $\mathrm{MCI}$ to $\mathrm{AD}$ dementia (Supplementary Table 5). LPA C16:1 and C16:0 levels in CSF are correlated with each other (Supplementary Fig. 2), which is also evident from their similar regression coefficient in the progression analysis. As a sensitivity analysis, we also performed cox proportional hazard analysis, additionally correcting for
APOE (Supplementary Table 6) and A $\beta-42$ levels in CSF (Supplementary Table 7) to assess the role of LPAs in MCI to AD progression. APOE did not affect the association of LPA C16:0 and C16:1 to MCI to $\mathrm{AD}$ dementia progression while the association was lost upon adjusting for $A \beta-42$ levels. In plasma, LPA C20:1 $\left(\beta=0.599, P=1.84 \times 10^{-2}\right)$ showed evidence of association to $\mathrm{MCI}$ to $\mathrm{AD}$ dementia progression but significance was lost upon adjusting for multiple testing (Supplementary Table 8). In the Heidelberg/ Mannheim sample (Supplementary Table 9), we did not replicate our findings from ACE cohort, i.e., LPA C16:1 $\left(\beta=0.457, P=8.91 \times 10^{-2}\right)$ and LPA C16:0 $(\beta=$ $\left.0.431, P=1.96 \times 10^{-1}\right)$.

\section{Association of cognitive measures with LPA levels}

We did not find significant association of LPA levels in CSF with MMSE and CDR score in the combined meta- 


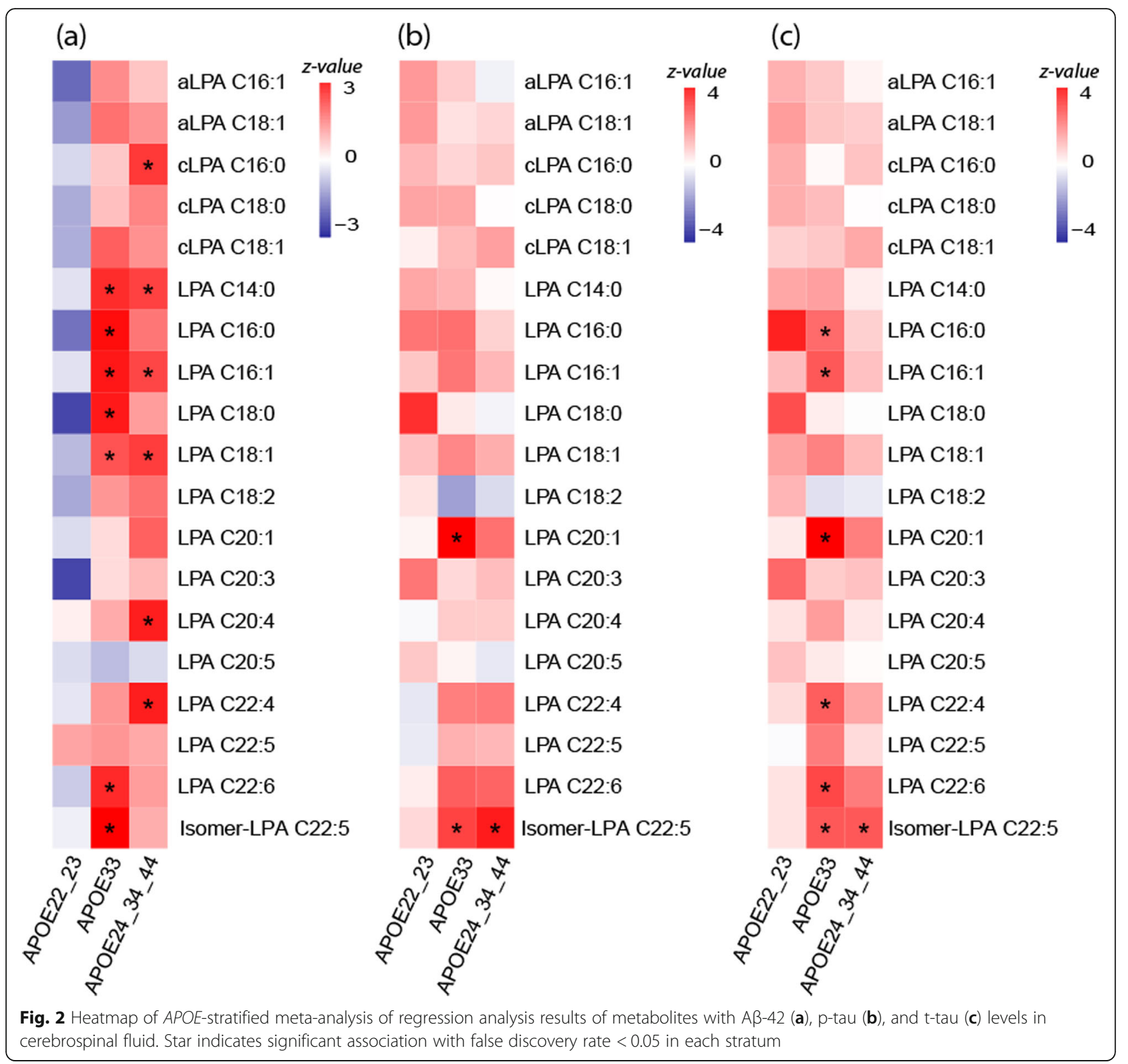

analysis (Supplementary Tables 10 and 11). In individual cohorts, only alkyl-LPA C16:1 showed evidence of association with MMSE $\left(\beta=0.253, P=4 \times 10^{-2}\right)$ in ACE cohort and with CDR score $\left(\beta=0.254, P=6.01 \times 10^{-3}\right)$ in Heidelberg/Mannheim sample.

\section{Discussion}

Meta-analysis of the data of two independent cohorts showed a significant association of eight LPAs to A $\beta-42$, six LPAs to p-tau, and eight LPAs to t-tau levels in CSF. In the $A P O E$-stratified meta-analysis, one cyclic LPA C16:0 and two LPAs (C20:4, C22:4) associate significantly with $\mathrm{A} \beta-42$ levels in APOE \&4 carriers only. The association of LPAs with p-tau and total tau were confined to $A P O E$ e33 carriers except for isomer-LPA C22:5, which showed association in both $A P O E 33$ and APOE4 strata. LPA C16:0 and C16:1 were associated with the progression of $\mathrm{MCI}$ to $\mathrm{AD}$ in the ACE cohort but the association was no longer significant after adjusting for $A \beta-42$ in the model.

The positive association between various LPAs and $A \beta-42$ is in line with the findings of an earlier study, suggesting that LPAs play a role in $A \beta$ production by upregulation of $\beta$-secretase (BACE1) [12], a key enzyme involved in the cleavage of amyloid precursor protein $(A P P)$. Our study pinpoints a key role of LPA C18:1, C16:1, C16:0, C22:6, C14:0, C22:4, C20:4, and isomerLPA C22:5 in CSF amyloid levels, detailing which 
specific LPAs are relevant. The association of LPA to CSF amyloid sheds new light on the role of (signaling) lipids in AD pathogenies. LPAs are a bioactive component of oxLDL, which show a positive correlation with CSF levels of $A \beta$ [48]. Moreover, traumatic brain injury (TBI) patients also exhibit increased CSF levels of LPAs [49]. Because amyloid pathology is observed in nearly $30 \%$ of TBI patients with unknown mechanisms [50], our observed positive association of amyloid pathology and LPA may suggest the role of LPAs as a mediator in the aggregation of amyloid pathology, which needs further investigation. On the other hand, $A \beta$ may increase oxidative stress and inflammation, which results in the production of LPAs. There is a need for functional studies to ascertain whether the positive correlation between amyloid and LPA is a cause or consequence of pathological process.

In our study, CSF levels of LPAs (C16:0 and C16:1) were significantly associated with $\mathrm{MCI}$ to $\mathrm{AD}$ dementia progression in the ACE cohort. Similar to the inverse relation of CSF $A \beta-42$ levels in MCI to AD dementia progression, decreased levels of the LPAs are associated with MCI to AD dementia progression [51]. Loss of association of LPAs with MCI to AD dementia progression when accounting for $A \beta-42$ levels suggests that $A \beta-42$ mediates the observed association of LPA C16:0 and C16:1 in conversion. This is of note that LPA 16:0 and 16:1 did not show significant association with MCI to $\mathrm{AD}$ progression in the smaller Heidelberg/Mannheim sample. However, LPA 16:0 and 16:1 also did not show significant association with $A \beta-42$ levels in this small cohort, making findings difficult to interpret. The fact that the association LPA C16:0 and C16:1 to conversion loses its significance when adjusting for $A \beta-42$ levels suggests the LPA C16:0 and C16:1 are likely preceding the changes in $\mathrm{A} \beta-42$ that predict conversion to $\mathrm{AD}$.

In the $A P O E$-stratified analysis, LPA C16:1 showed a positive association to A $\beta-42$ levels in both $A P O E \varepsilon 4$ and $A P O E$ \&33 carriers, whereas LPA C16:0 showed significant positive association in only $A P O E \varepsilon 3$ stratum. No effect of the ratio of these two correlated LPAs was seen. The findings imply that the association of these LPAs to A $\beta-42$ levels may be modified by APOE genotype of the person. To our knowledge, this is the first study that shows the $A P O E$ interacts with LPA in humans. Interestingly, all LPA showed a negative association with $A \beta-42$ in $A P O E \varepsilon 2$ carriers, i.e., in the opposite direction compared to $A P O E \varepsilon 33$ and $A P O E \varepsilon 4$ carrier. Since $A P O E \varepsilon 2$ carriers are protected from $\mathrm{AD}$ and have delayed onset of AD [46], LPA modification may be relevant in $A P O E$ $\varepsilon 33$ and $A P O E$ \&4 carriers. We did not observe an association of the interacting LPAs with $A P O E$ genotypes, which may be due to a limited sample size in these analyses.
Except for LPA C16:0, we found that the majority of unsaturated LPAs (C16:1, C20:1, isomer-LPA C22:5, $\mathrm{C} 22: 6$, and $\mathrm{C} 22: 4$ ) showed significant association to both p-tau and total tau levels in CSF. Due to differential activation of LPA receptors by diverse LPA metabolite species [23], association of unsaturated LPAs with $\mathrm{AD}$ biomarkers of pathophysiology can also be explained by their affinity for $\mathrm{LPA}_{3}$ receptors [52] which are also expressed in hippocampus, frontal cortex, and amygdala [53]. Moreover, both saturated and unsaturated LPAs are reported to influence $\mathrm{Ca}^{2+}$ signaling through LPA2 receptors [52], which may also suggest their involvement in the dysregulation of $\mathrm{Ca}^{2+}$ signaling in $\mathrm{AD}$. Earlier studies have shown that LPAs acts as mediators to maintain the intracellular $\mathrm{Ca}^{2+}$ levels in both astrocytes [54] and microglial cells $[5,55]$. One of these LPAs (LPA C20:1) only showed significant association with p-tau and total tau levels but not with $A \beta-42$. These tau specific associations may be explained by the fact that LPAs are involved in the upregulation of glycogen synthase kinase-3 (GSK-3), an enzyme involved in phosphorylation of tau and thus may influence levels of p-tau in CSF $[13,56]$. The association of LPA C20:1 to only tau pathology may also indicate the specificity of association of LPA species of different acyl chains to different AD pathophysiological mechanisms. In the $A P O E$-stratified meta-analysis, all the observed associations were largely confined to $A P O E$ \&33 carriers except for isomer-LPA C22:5. This observation is in line with the studies which demonstrated that $A P O E \& 4$ may influence amyloid pathology in the brain rather than tau aggregation [57-59].

We did not observe association of LPA levels in plasma with $A \beta-42$, p-tau, and total-tau in CSF nor did we find association with $\mathrm{MCI}$ to $\mathrm{AD}$ dementia progression. It is interesting that we observed a significant correlation between CSF and plasma measurements of various LPA molecular species. A negative correlation was observed for cyclic-LPA C16:0, cyclic-LPA C18:1, and LPA C20:1. Of these, the association was strongest and most convincing for LPA C20:1 in terms of $R$ $(-0.23)$ and $p$ value $6.2 \times 10^{-3}$. The positive correlations are more convincing in particular for LPA C18:1 $(R=0.44$ and $\left.P=4.5 \times 10^{-8}\right)$ and $C 20: 5\left(R=0.40\right.$ and $\left.P=1.2 \times 10^{-6}\right)$ and LPA 22:4 $\left(R=0.27\right.$ and $\left.P=1.2 \times 10^{-3}\right)$ (Supplementary Fig. 1). LPAs found associated with $A \beta$, p-tau and ttau in CSF were not correlated with their counterparts in plasma, which indicates that the LPA role in relation to $\mathrm{AD}$ pathology is primarily cerebral and not in the circulation.

Our study provides a comprehensive overview of association of various LPA species including alkyl-LPAs and cyclic-LPAs to biomarkers of AD during the prodromal phase. The inclusion of two independent cohorts is a major strength of our investigation, allowing us to check 
consistency of effect across cohorts. Moreover, we have also assessed the role of LPAs longitudinally for MCI to $\mathrm{AD}$ dementia progression in the ACE cohort.

\section{Limitations}

The short follow-up time for MCI patients in the progression study is a limitation of our study and asks for replication in a study with longer follow-up. The small sample size in $\mathrm{MCI}$ to $\mathrm{AD}$ progression analysis is another major limitation of our study. In the absence of any data on the association between LPA and AD biomarkers in CSF, we did not perform a power calculation a priori, which limits the clinical and predictive implications of the discovery analysis. Future large sample sizes in follow-up studies will also provide more power to perform $A P O E$-stratified analysis.

\section{Conclusions}

Overall findings from our study suggest that various LPAs based on acyl chain length and saturation level are associated with $A \beta-42$, p-tau, and total tau levels. Our study suggests the role of LPAs in the pathophysiology of $\mathrm{AD}$. Future studies are needed to determine whether LPA metabolites triggers various biological pathways leading to increase in biomarkers of $\mathrm{AD}$ pathophysiology or are produced as a downstream effect of $\mathrm{AD}$ pathology. We further find that $A P O E$ may influence the association between LPAs and $A \beta-42$.

\section{Supplementary information}

Supplementary information accompanies this paper at https://doi.org/10. 1186/s13195-020-00680-9.

Additional file 1: Table S1. List of detected lysophosphatidic acids in cerebrospinal fluid and plasma. Table S2. Association of metabolites in plasma association with amyloid-beta 42, P-Tau and total tau. Table S3. Association of metabolites in cerebrospinal fluid with APOE 22/23 versus $A P O E$ 33. Table S4. Association of metabolites in cerebrospinal fluid with APOE 44/34/24 vS APOE 33. Table S5. Association of metabolites measured in CSF with $\mathrm{MCl}$ to $\mathrm{AD}$ conversion in ACE cohort. Table S6. Association of metabolites measured in CSF with MCI to AD conversion adjusting for APOE in ACE cohort. Table S7. Association of metabolites measured in CSF with $\mathrm{MCl}$ to AD conversion adjusted for amyloid beta 42 levels in ACE cohort. Table S8. Association of metabolites measured in plasma with $\mathrm{MCl}$ to $\mathrm{AD}$ conversion in ACE cohort. Table S9. Association of metabolites measured in CSF with $\mathrm{MCI}$ to $\mathrm{AD}$ conversion in Heidelberg/Mannheim sample. Table S10. Association of the Mini-Mental State Examination (MMSE) with LPAs in CSF. Table S11. Association of the clinical dementia score (CDR) with LPAs in CSF. Figure S1. Correlation of metabolite levels between plasma and CSF. Figure S2. Correlation matrix of CSF LPA metabolites.

\section{Abbreviations}

AD: Alzheimer's disease; LPAs: Lysophosphatidic acids; APOE: Apolipoprotein E; MCl: Mild cognitive impairment; CSF: Cerebrospinal fluid; $\mathrm{p}$ tau: Phosphorylated tau ( $p$-tau); t-tau: Total tau; AB: Amyloid-beta; ADAP TED: The Alzheimer's Disease Apolipoprotein Pathology for Treatment Elucidation and Development consortium; BMl: Body mass index; ACE: The Fundació ACE cohort; FDR: False discovery rate

\section{Acknowledgements}

This study was funded by the ADAPTED: Alzheimer's Disease Apolipoprotein Pathology for Treatment Elucidation and Development consortium which has received funding from the Innovative Medicines Initiative 2 Joint Undertaking under Grant Agreement No 115975. This Joint Undertaking receives support from the European Union's Horizon 2020 research and innovation programme and the European Federation of Pharmaceutical Industries and Associations. Part of this work was supported by the JPND EADB grant (German Federal Ministry of Education and Research, BMBF: 01ED1619A).

We acknowledge all patients participating in this study from Fundació ACE and Heidelberg-Mannheim memory clinic. We also want to thank the investigators from the Fundació ACE Barcelona Alzheimer Treatment and Research Center, for their close collaboration and continuous intellectual input. We are grateful to Laura Montrreal for her exceptional technical support. A.R. and M.B. receive support from the European Union/EFPIA Innovative Medicines Initiative Joint Undertaking ADAPTED and MOPEAD projects (Grants No. 115975 and 115985, respectively). M.B., S.G., and A.R. are also supported by national grants PI13/02434, PI16/01861, and PI17/01474. Acción Estratégica en Salud is integrated into the Spanish National R + D + I Plan and funded by ISCIII (Instituto de Salud Carlos III)-Subdirección General de Evaluación and the Fondo Europeo de Desarrollo Regional (FEDER- "Una manera de Hacer Europa").

\section{Authors' contributions}

Study concept and design: S.A., A.R., A.R., T.H., C.M.D. Draft of the manuscript: S.A. Performed statistical analysis: S.A., Interpretation of data: S.A., A.O., I.K., L.F., I.R., S.G., M.B., I.H., L.H., M.H.M.B., A.C., N.A., A.R., A.R., T.H., C.M.D. All authors reviewed and approved the manuscript.

\section{Funding}

N/A

\section{Availability of data and materials}

Data can only be available upon request for only research purposes. The availability of data will be possible in compliance with EU-GDPR rules. Data access requests can be made directly to the corresponding authors.

\section{Ethics approval and consent to participate}

Fundació ACE cohort has been approved by the ethic committee of the Hospital Clinic i Provincial de Barcelona in Barcelona, Spain, in accordance with Spanish biomedical laws (Law 14/2007, July 3rd, about biomedical research; Royal Decree 1716/2011, November 18th) and followed the recommendations of the Declaration of Helsinki.

\section{Consent for publication}

All the samples from the Fundació ACE cohort and the Heidelberg/ Mannheim memory clinic have the informed consent of the subjects that have donated them. In the Fundació ACE cohort, these protocols of consent have been approved previously by Ethics Committee of the Hospital Clínic (HCB/2014/0494, HCB/2016/0571, HCB/2016/0835, HCB/2017/0125, and HCB/ 2018/0333). The protocols have been designed in agreement with the indications of the Sociedad Española de Neurologiaaccording to the current normative for the use of clinical data and biological material and surplus of the assisted process for the biomedicine research of neurodegenerative diseases.

\section{Competing interests}

S.A., A.O., I.K., L.F., I.R., S.G., M.B., I.H., L.H., N.A., A.R., A.R., T.H., and C.M.D declared no competing interests. Margot H.M. Bakker is a full-time employee of AbbVie Deutschland GmbH \& Co KG and owns AbbVie stock. Alfredo Cabrera-Socorro is full-time employee of Janssen Pharmaceutical NV Turnhoutseweg 30, 2340 Beerse, Belgium.

\section{Author details}

${ }^{1}$ Department of Epidemiology, Erasmus Medical Centre, Rotterdam, The Netherlands. ${ }^{2}$ Research Center and Memory Clinic Fundació ACE, Institut Català de Neurociències, Aplicades. Universitat Internacional de Catalunya, Barcelona, Spain. ${ }^{3}$ Centro de Investigación Biomédica en Red de Enfermedades Neurodegenerativas (CIBERNED), Instituto de Salud Carlos III, Madrid, Spain. ${ }^{4}$ Division of Systems Biomedicine and Pharmacology, Leiden 
Academic Centre for Drug Research, Leiden University, Leiden, The Netherlands. ${ }^{5}$ Department of Geriatric Psychiatry, Central Institute of Mental Health, Medical Faculty Mannheim, University of Heidelberg, 68159 Mannheim, Germany. ${ }^{6}$ Institute of Cognitive and Clinical Neuroscience, Central Institute of Mental Health, Medical Faculty Mannheim, Heidelberg University, 68159 Mannheim, Germany. ${ }^{7}$ Discovery Research, AbbVie Deutschland GmbH \& Co. KG, Knollstrasse, 67061 Ludwigshafen, Germany. ${ }^{8}$ Janssen Pharmaceutical NV, Turnhoutseweg 30, 2340 Beerse, Belgium. ${ }^{9}$ Department for Neurodegenerative Diseases and Geriatric Psychiatry, University of Bonn, Bonn, Germany. ${ }^{10}$ Division of Neurogenetics and Molecular Psychiatry, Department of Psychiatry and Psychotherapy, Medical Faculty, University of Cologne, Cologne, Germany. ${ }^{11}$ Nuffield Department of Population Health, Oxford University, Oxford, UK.

\section{Received: 4 May 2020 Accepted: 9 September 2020} Published online: 02 October 2020

\section{References}

1. Varma VR, Oommen AM, Varma S, Casanova R, An Y, Andrews RM, et al. Brain and blood metabolite signatures of pathology and progression in Alzheimer disease: a targeted metabolomics study. PLoS Med. 2018;15(1): e1002482.

2. van der Lee SJ, Teunissen CE, Pool R, Shipley MJ, Teumer A, Chouraki V, et al. Circulating metabolites and general cognitive ability and dementia: evidence from 11 cohort studies. Alzheimers Dement. 2018;14(6):707-22.

3. Liu Q, Zhang J. Lipid metabolism in Alzheimer's disease. Neurosci Bull. 2014; 30(2):331-45. https://doi.org/10.1007/s12264-013-1410-3 PubMed PMID: 24733655; PubMed Central PMCID: PMCPMC5562656.

4. Yung YC, Stoddard NC, Mirendil H, Chun J. Lysophosphatidic acid signaling in the nervous system. Neuron. 2015;85(4):669-82. https://doi.org/10.1016/j. neuron.2015.01.009 Epub 2015/02/20 PubMed PMID: 25695267; PubMed Central PMCID: PMC4400838.

5. Schilling T, Stock C, Schwab A, Eder C. Functional importance of Ca2+activated $\mathrm{K}+$ channels for lysophosphatidic acid-induced microglial migration. Eur J Neurosci. 2004;19(6):1469-74.

6. Anliker B, Choi JW, Lin ME, Gardell SE, Rivera RR, Kennedy G, et al. Lysophosphatidic acid (LPA) and its receptor, LPA1, influence embryonic schwann cell migration, myelination, and cell-to-axon segregation. Glia. 2013;61(12):2009-22.

7. Armati PJ, Mathey EK. An update on Schwann cell biology_immunomodulation, neural regulation and other surprises. $J$ Neurol Sci. 2013;333(1-2):68-72.

8. Garcia-Morales V, Montero F, Gonzalez-Forero D, Rodriguez-Bey G, GomezPerez L, Medialdea-Wandossell MJ, et al. Membrane-derived phospholipids control synaptic neurotransmission and plasticity. PLoS Biol. 2015;13(5): e1002153. https://doi.org/10.1371/journal.pbio.1002153.

9. Robinson R. One lipid, two synaptic plasticity pathways. Plos Biology. 2015; 13(5):e1002154-e.

10. Yukiura H, Hama K, Nakanaga K, Tanaka M, Asaoka Y, Okudaira S, et al. Autotaxin regulates vascular development via multiple lysophosphatidic acid (LPA) receptors in zebrafish. J Biol Chem. 2011;286(51):43972-83.

11. de Leeuw FA, Peeters CF, Kester MI, Harms AC, Struys EA, Hankemeier T, et al. Blood-based metabolic signatures in Alzheimer's disease. Alzheimer's \& Dementia: Diagnosis, Assessment \& Disease Monitoring. 2017:8:196-207.

12. Shi J, Dong Y, Cui M-Z, Xu X. Lysophosphatidic acid induces increased BACE1 expression and A $\beta$ formation. Biochimica et Biophysica Acta (BBA)Molecular Basis of Disease. 2013;1832(1):29-38.

13. Sayas CL, Moreno-Flores MT, Avila J, Wandosell F. The neurite retraction induced by lysophosphatidic acid increases Alzheimer's disease-like Tau phosphorylation. J Biol Chem. 1999;274(52):37046-52. Epub 1999/12/22 PubMed PMID: 10601262. https://doi.org/10.1074/jbc.274.52.37046.

14. Frisardi V, Panza F, Seripa D, Farooqui T, Farooqui AA. Glycerophospholipids and glycerophospholipid-derived lipid mediators: a complex meshwork in Alzheimer's disease pathology. Prog Lipid Res. 2011;50(4):313-30.

15. Draczynska-Lusiak B, Doung A, Sun AY. Oxidized lipoproteins may play a role in neuronal cell death in Alzheimer disease. Mol Chem Neuropathol. 1998;33(2):139-48. https://doi.org/10.1007/BF02870187 PubMed PMID: 9565971.

16. Holtsberg FW, Steiner MR, Bruce-Keller AJ, Keller JN, Mattson MP, Moyers JC, et al. Lysophosphatidic acid and apoptosis of nerve growth factordifferentiated PC12 cells. J Neurosci Res. 1998;53(6):685-96.
17. Uranbileg B, Ito N, Kurano M, Saigusa D, Saito R, Uruno A, et al. Alteration of the lysophosphatidic acid and its precursor lysophosphatidylcholine levels in spinal cord stenosis: a study using a rat cauda equina compression model. Sci Rep. 2019;9(1):1-13.

18. Ramesh S, Govindarajulu M, Suppiramaniam V, Moore T, Dhanasekaran M. Autotaxin(-)lysophosphatidic acid signaling in Alzheimer's disease. Int J Mol Sci. 2018;19(7). doi: https://doi.org/10.3390/ijms19071827. PubMed PMID: 29933579; PubMed Central PMCID: PMCPMC6073975.

19. Hayakawa K, Kurano M, Ohya J, Oichi T, Kano K, Nishikawa M, et al. Lysophosphatidic acids and their substrate lysophospholipids in cerebrospinal fluid as objective biomarkers for evaluating the severity of lumbar spinal stenosis. Sci Rep. 2019;9(1):1-9.

20. Aoki J, Inoue A, Okudaira S. Two pathways for lysophosphatidic acid production. Biochimica et Biophysica Acta (BBA)-Molecular and Cell Biology of Lipids. 2008;1781(9):513-518.

21. Cho H-J, Choi S-H, Kim H-J, Lee B-H, Rhim H, Kim H-C, et al. Bioactive lipids in gintonin-enriched fraction from ginseng. J Ginseng Research. 2019;43(2): 209-17.

22. Takeda A, Umemoto E, Miyasaka M. Lysophosphatidic acid as a regulator of lymphocyte trafficking in the lymph nodes. Transl Cancer Res. 2015;4(5): 537-43.

23. Bandoh K, Aoki J, Taira A, Tsujimoto M, Arai H, Inoue K. Lysophosphatidic acid (LPA) receptors of the EDG family are differentially activated by LPA species: structure-activity relationship of cloned LPA receptors. FEBS Lett. 2000;478(1-2):159-65.

24. Yoshida K, Nishida W, Hayashi Ki, Ohkawa Y, Ogawa A, Aoki J, et al. Vascular remodeling induced by naturally occurring unsaturated lysophosphatidic acid in vivo. Circulation. 2003;108(14):1746-1752.

25. Aikawa S, Hashimoto T, Kano K, Aoki J. Lysophosphatidic acid as a lipid mediator with multiple biological actions. J Biochem. 2015;157(2):81-9. https://doi.org/10.1093/jb/mvu077 PubMed PMID: 25500504.

26. Moolenaar WH. Lysophosphatidic acid, a multifunctional phospholipid messenger. J Biol Chem. 1995;270(22):12949-52.

27. Boada M, Tarraga L, Hernandez I, Valero S, Alegret M, Ruiz A, et al. Design of a comprehensive Alzheimer's disease clinic and research center in Spain to meet critical patient and family needs. Alzheimers Dement. 2014;10(3):40915. doi: https://doi.org/10.1016/j.jalz.2013.03.006. PubMed PMID: 24035148; PubMed Central PMCID: PMCPMC3951687.

28. Petersen RC. Mild cognitive impairment as a diagnostic entity. J Intern Med. 2004;256(3):183-94. https://doi.org/10.1111/j.1365-2796.2004.01388.x PubMed PMID: 15324362.

29. Petersen RC, Smith GE, Waring SC, Ivnik RJ, Tangalos EG, Kokmen E. Mild cognitive impairment: clinical characterization and outcome. Arch Neurol. 1999:56(3):303-8 PubMed PMID: 10190820.

30. Edition F. Diagnostic and statistical manual of mental disorders. Am Psychiatric Assoc. 2013.

31. McKhann GM, Knopman DS, Chertkow H, Hyman BT, Jack CR Jr, Kawas CH, et al. The diagnosis of dementia due to Alzheimer's disease: recommendations from the National Institute on Aging-Alzheimer's Association workgroups on diagnostic guidelines for Alzheimer's disease. Alzheimers Dement. 2011;7(3):263-9.

32. Román GC, Tatemichi TK, Erkinjuntti T, Cummings J, Masdeu J, Garcia J, et al. Vascular dementia: diagnostic criteria for research studies: report of the NINDS-AIREN International Workshop. Neurology. 1993;43(2):250.

33. Mesulam MM, Grossman M, Hillis A, Kertesz A, Weintraub S. The core and halo of primary progressive aphasia and semantic dementia. Annals of Neurol. 2003:54(S5):S11-S4.

34. Halliday G, Lewis S, Aarsland D, Attems J, Ballard CG, Boeve BF, et al. Diagnosis and management of dementia with Lewy bodies. 2017

35. Vanderstichele $H$, Bibl M, Engelborghs S, Le Bastard N, Lewczuk P, Molinuevo JL, et al. Standardization of preanalytical aspects of cerebrospinal fluid biomarker testing for Alzheimer's disease diagnosis: a consensus paper from the Alzheimer's Biomarkers Standardization Initiative. Alzheimers Dement. 2012;8(1):65-73. https://doi.org/10.1016/j.jalz.2011.07.004 PubMed PMID: 22047631

36. Vanderstichele H, De Meyer G, Shapiro F, Engelborghs S, De Deyn PP, Shaw LM, et al. Biomarkers for early diagnosis of Alzheimer's disease. Hauppauge, NY: Nova Science Publishers; 2008.

37. Winblad B, Palmer K, Kivipelto M, Jelic V, Fratiglioni L, Wahlund LO, et al. Mild cognitive impairment--beyond controversies, towards a consensus: report of the International Working Group on Mild Cognitive Impairment. J 
Intern Med. 2004;256(3):240-6. https://doi.org/10.1111/j.1365-2796.2004. 01380.x PubMed PMID: 15324367.

38. Morris JC, Heyman A, Mohs RC, Hughes JP, van Belle G, Fillenbaum G, et al. The Consortium to Establish a Registry for Alzheimer's Disease (CERAD). Part I. Clinical and neuropsychological assessment of Alzheimer's disease. Neurology. 1989:39(9):1159-65. https://doi.org/10.1212/wnl.39.9.1159 PubMed PMID: 2771064

39. Walton D. The diagnostic and predictive accuracy of the Wechsler Memory Scale in psychiatric patients over 65. J Ment Sci. 1958;104(437):1111-8.

40. Reitan RM, Wolfson D. The Trail Making Test as an initial screening procedure for neuropsychological impairment in older children. Arch Clin Neuropsychol. 2004;19(2):281-8.

41. Albert MS, Dekosky ST, Dickson D, Dubois B, Feldman HH, Fox NC, et al. The diagnosis of mild cognitive impairment due to Alzheimer's disease: recommendations from the National Institute on Aging-Alzheimer's Association workgroups on diagnostic guidelines for Alzheimer's disease. Alzheimers Dement. 2011;7(3):270-9. doi: https://doi.org/10.1016/j.jalz.2011. 03.008. PubMed PMID: 21514249; PubMed Central PMCID: PMCPMC3312027.

42. Kaerst L, Kuhlmann A, Wedekind D, Stoeck K, Lange P, Zerr I. Cerebrospinal fluid biomarkers in Alzheimer's disease, vascular dementia and ischemic stroke patients: a critical analysis. J Neurol. 2013;260(11):2722-7. doi: https:// doi.org/10.1007/s00415-013-7047-3. PubMed PMID: 23877436; PubMed Central PMCID: PMCPMC3825487.

43. Schoeman JC, Harms AC, van Weeghel M, Berger R, Vreeken RJ, Hankemeier T. Development and application of a UHPLC-MS/MS metabolomics based comprehensive systemic and tissue-specific screening method for inflammatory, oxidative and nitrosative stress. Anal Bioanal Chem. 2018; 410(10):2551-68. doi: https://doi.org/10.1007/s00216-018-0912-2. PubMed PMID: 29497765; PubMed Central PMCID: PMCPMC5857282.

44. Willer CJ, Li Y, Abecasis GR. METAL: fast and efficient meta-analysis of genomewide association scans. Bioinformatics. 2010;26(17):2190-1. https:// doi.org/10.1093/bioinformatics/btq340 Epub 2010/07/10 PubMed PMID: 20616382; PubMed Central PMCID: PMC2922887.

45. Benjamini Y, Hochberg Y. Controlling the false discovery rate: a practical and powerful approach to multiple testing. J Royal Statistical Society Series B (Methodological). 1995:289-300.

46. van der Lee SJ, Wolters FJ, Ikram MK, Hofman A, Ikram MA, Amin N, et al. The effect of APOE and other common genetic variants on the onset of Alzheimer's disease and dementia: a community-based cohort study. Lancet Neurol. 2018;17(5):434-44. Epub 2018/03/21 PubMed PMID: 29555425. https://doi.org/10.1016/S1474-4422(18)30053-X.

47. Mitchell AJ, Shiri-Feshki M. Rate of progression of mild cognitive impairment to dementia--meta-analysis of 41 robust inception cohort studies. Acta Psychiatr Scand. 2009;119(4):252-65. https://doi.org/10.1111/j.1600-0447. 2008.01326.x Epub 2009/02/25 PubMed PMID: 19236314

48. Sun $Y-X$, Minthon L, Wallmark A, Warkentin S, Blennow $K$, Janciauskiene $S$. Inflammatory markers in matched plasma and cerebrospinal fluid from patients with Alzheimer's disease. Dement Geriatr Cogn Disord. 2003;16(3): 136-44.

49. McDonald WS, Jones EE, Wojciak JM, Drake RR, Sabbadini RA, Harris NG. Matrix-assisted laser desorption ionization mapping of lysophosphatidic acid changes after traumatic brain injury and the relationship to cellular pathology. Am J Pathol. 2018;188(8):1779-93.

50. Sivanandam TM, Thakur MK. Traumatic brain injury: a risk factor for Alzheimer's disease. Neurosci Biobehav Rev. 2012;36(5):1376-81

51. Hampel H, Teipel SJ, Fuchsberger T, Andreasen N, Wiltfang J, Otto M, et al. Value of CSF $\beta$-amyloid 1-42 and tau as predictors of Alzheimer's disease in patients with mild cognitive impairment. Mol Psychiatry. 2004;9(7):705.

52. Bandoh K, Aoki J, Hosono H, Kobayashi S, Kobayashi T, Murakami-Murofushi $\mathrm{K}$, et al. Molecular cloning and characterization of a novel human G-proteincoupled receptor, EDG7, for lysophosphatidic acid. J Biol Chem. 1999; 274(39):27776-85. https://doi.org/10.1074/jbc.274.39.27776 PubMed PMID: 10488122.

53. Im DS, Heise CE, Harding MA, George SR, O'Dowd BF, Theodorescu D, et al. Molecular cloning and characterization of a lysophosphatidic acid receptor, Edg-7, expressed in prostate. Mol Pharmacol. 2000;57(4):753-9 PubMed PMID: 10727522

54. Keller JN, Steiner MR, Holtsberg FW, Mattson MP, Steiner SM. Lysophosphatidic acid-induced proliferation-related signals in astrocytes J Neurochem. 1997;69(3):1073-84
55. Schilling T, Repp H, Richter H, Koschinski A, Heinemann U, Dreyer F, et al. Lysophospholipids induce membrane hyperpolarization in microglia by activation of IKCa1 Ca2+-dependent K+ channels. Neuroscience. 2002; 109(4):827-35.

56. Sayas C, Avila J, Wandosell F. Regulation of neuronal cytoskeleton by lysophosphatidic acid: role of GSK-3 Biochimica et Biophysica Acta (BBA)Molecular and Cell Biology ofLipids. 2002;1582(1-3):144-153.

57. Morris JC, Roe CM, Xiong C, Fagan AM, Goate AM, Holtzman DM, et al. APOE predicts amyloid-beta but not tau Alzheimer pathology in cognitively normal aging. Ann Neurol. 2010;67(1):122-31,

58. Sunderland T, Mirza N, Putnam KT, Linker G, Bhupali D, Durham R, et al. Cerebrospinal fluid $\beta$-amyloid1-42 and tau in control subjects at risk for Alzheimer's disease: the effect of APOE $\varepsilon 4$ allele. Biol Psychiatry. 2004;56(9): 670-6.

59. Huang YA, Zhou B, Wernig M, Sudhof TC. ApoE2, ApoE3, and ApoE4 differentially stimulate APP transcription and Abeta secretion. Cell. 2017; 168(3):427-41. https://doi.org/10.1016/j.cell.2016.12.044 e21. Epub 2017/01/ 24 PubMed PMID: 28111074; PubMed Central PMCID: PMC5310835.

\section{Publisher's Note}

Springer Nature remains neutral with regard to jurisdictional claims in published maps and institutional affiliations.

\section{Ready to submit your research? Choose BMC and benefit from:}

- fast, convenient online submission

- thorough peer review by experienced researchers in your field

- rapid publication on acceptance

- support for research data, including large and complex data types

- gold Open Access which fosters wider collaboration and increased citations

- maximum visibility for your research: over $100 \mathrm{M}$ website views per year

At BMC, research is always in progress.

Learn more biomedcentral.com/submissions 